\title{
AS POLÍTICAS ESTATAIS E A INDÚSTRIA CINEMATOGRÁFICA BRASILEIRA
}

\author{
Elton Moreira Quadros ${ }^{1}$ \\ Elton Silva Salgado ${ }^{2}$
}

BAHIA, Lia. Discursos, políticas e ações: processos de industrialização do campo cinematográfico brasileiro. São Paulo: Itaú Cultural: Iluminuras, 2012.

O cinema no Brasil esteve, em diversos momentos de nossa história, com significativo destaque, quer seja comercial, quer seja artístico, quer seja como elemento de reflexão sobre o mundo e sobre a nossa identidade. No entanto, muito ainda será necessário percorrer para que tenhamos uma pesquisa mais concreta e acadêmica, que possibilitará um conhecimento mais efetivo do processo de industrialização da produção cinematográfica brasileira.

Como sabemos, apesar da sua riqueza, complexidade e presença na vida cotidiana, o campo cultural ainda encontra muitas dificuldades para ser estudado, para servir como objeto de pesquisa. Isso se deve tanto à delicadeza da realização da coleta de dados, quanto aos obstáculos que essas pesquisas encontram para conseguir publicação e distribuição, mesmo quando já estão em formato de livro, dificultando a existência de um ambiente de troca efetiva de informações.

Neste contexto, encontramos o livro Discursos, políticas e ações: processos de industrialização do campo cinematográfico brasileiro, de Lia Bahia, fruto de sua pesquisa de Mestrado, no Programa de Pós-Graduação de Comunicação, da Universidade Federal Fluminense (PPGCOM/UFF). Este trabalho foi laureado com o prêmio Itaú Cultural, tendo a sua publicação realizada por meio da editora Iluminuras, em 2012, passando a fazer, assim, parte da Coleção Rumos Pesquisa Gestão Cultural.

Lia Bahia aborda a relação, tão efetiva quando pensamos a Sétima Arte, entre a produção cinematográfica e a indústria do cinema no Brasil. Algumas das perguntas

\footnotetext{
${ }^{1}$ Universidade Estadual do Sudoeste da Bahia (UESB), Vitória da Conquista - Bahia - Brasil. Doutor em Memória: Linguagem e Sociedade, pela Universidade Estadual do Sudoeste da Bahia (UESB). É professor do Departamento de Educação, do Programa de Pós-Graduação em Ecologia Humana e Gestão Socioambiental, da Universidade do Estado da Bahia (UNEB) e, do Programa de Pós-Graduação em Memória: Linguagem e Sociedade, da Universidade Estadual do Sudoeste da Bahia (UESB). ORCID $<$ https://orcid.org/0000-00032802-5990>. E-mail: eltonquadros@yahoo.com.br.

${ }^{2}$ Universidade Estadual do Sudoeste da Bahia (UESB), Vitória da Conquista - Bahia - Brasil. Doutor em Memória: Linguagem e Sociedade, pela Universidade Estadual do Sudoeste da Bahia (UESB). É professor da Faculdade Maurício de Nassau e Coordenador do Centro de Cultura Camillo de Jesus Lima, ligado a Secretaria de Cultura do Estado da Bahia (Secult - BA). E-mail: elton.becker@me.com.
} 


\section{Linguagens - Revista de Letras, Artes e Comunicação - ISSN 1981- 9943 \\ Blumenau, v. 12, n. 2, p. 360-364, mai./ago. 2018. \\ DOI: http://dx.doi.org/10.7867/1981-9943.2018v12n2p361-365}

afrontadas pela autora são: qual o papel do Estado e da industrialização do campo cinematográfico? Quais as conexões e dificuldades entre o que está nas leis de incentivo, nos discursos políticos e na prática efetiva das políticas para o cinema e o audiovisual no Brasil? Qual o peso do setor televisivo neste processo?

A pesquisa pretende responder a essas perguntas em três capítulos, que serão responsáveis por realizar um recorte histórico, apresentando elementos da relação brasileira entre o cinema e o Estado, com destaque para os aspectos econômicos, ideológicos e culturais da história do cinema no Brasil além de cobrir uma lacuna sobre nossa história, uma vez que

[...] a historiografia clássica do cinema brasileiro é essencialmente relativa às narrativas sobre a arte cinematográfica: sua estética, linguagem, diretores, realizadores e atores. $\mathrm{O}$ mercado, a legislação, as políticas públicas, os espectadores e a relação com a produção, distribuição e exibição quase sempre ficaram à margem dos estudos sobre a cinematografia (BAHIA, 2012, p. 19).

Por isso, esse olhar possibilita compreender também que, entre nós, houve um entendimento, desde o seu início, que a sétima arte precisaria de uma regulamentação estatal, quer do ponto de vista de difusão de uma identidade nacional, quer por conta de seus aspectos econômicos, que poderiam estar associados ao desenvolvimento do país.

No primeiro capítulo, intitulado Outra história do cinema nacional: cultura, indústria, desenvolvimento e mercado, são apresentados os movimentos iniciais da indústria cinematográfica no Brasil, que começa na década de 1930, com algumas ações na década de 1940. Entretanto, essa indústria só ganha maiores contornos mesmo nos anos 1950, quando, em 1956, foi criada o Grupo de Estudos da Indústria Cinematográfica (Geic), logo seguido pela criação do Grupo Executivo da Indústria Cinematográfica (Geincine), em 1961. Só nesses dois atos e na compreensão apresentada por cada um desses grupos, temos um retrato inicial do que seria a mentalidade que dominaria dialeticamente a visão sobre a produção cinematográfica no Brasil.

De um lado, encontramos os defensores do cinema como uma atividade pertencente à iniciativa privada e que só precisaria do Estado como regulador, especialmente do mercado, sem maiores ingerências no conteúdo ou no processo artístico. Do outro lado, temos uma visão que pretende tornar a indústria do cinema uma promotora da identidade nacional ou de uma reflexão cultural sobre o próprio país. Neste ponto, encontramos o apoio à ideia de que o Estado deve assegurar a existência desse campo cinematográfico no mercado competitivo e dispendioso da indústria cinematográfica em nome da própria nação. 


\section{Linguagens - Revista de Letras, Artes e Comunicação - ISSN 1981- 9943 \\ Blumenau, v. 12, n. 2, p. 360-364, mai./ago. 2018. \\ DOI: http://dx.doi.org/10.7867/1981-9943.2018v12n2p361-365}

A Embrafilme, criada no final da década de 1960, coloca em prática a noção de que a indústria cinematográfica brasileira poderia desenvolver-se, desde que fosse com recursos nacionais. Em alguma medida, o cinema no Brasil esteve permanentemente lutando para fazer frente à supremacia da produção estrangeira. A existência da Embrafilme, nos seus mais de 20 anos, possibilitou a produção de muitos filmes, alcançando, em alguns períodos, uma média anual superior a 30 filmes.

Apesar disso, a realidade comercial da produção cinematográfica brasileira esteve sempre numa dificuldade econômica tal, que inviabilizou chegarmos a um estágio autossustentável. Com exceções ocasionais, o cinema, desde as suas origens até hoje, ainda mantém uma dependência da subvenção estatal ou das leis de incentivo à cultura.

No segundo capítulo, intitulado Mercado de cinema no Brasil sob a égide do Estado regulador: desencaixes culturais e econômicos, a abordagem está mais intimamente ligada aos acontecimentos dos anos 2000 e toda a realidade daquele momento, em que a globalização coloca a cultura local em efetiva relação com os eventos mundiais e cria uma espécie de "mundialização da cultura". Por isso, foi necessário pensar em novas bases o fazer cinema, além disso, agora, acredita Lia Bahia (2012), seria preciso constatar que tanto o controle cultural quanto o livre mercado são questionados.

O marco significativo das discussões sobre o cinema no Brasil está no III Congresso Brasileiro de Cinema, realizado em 2000. Nele, houve um entendimento de que era preciso repolitizar, reorganizar, remobilizar tanto a política de cinema quanto às políticas públicas para o cinema. Nesse congresso, a comunidade cinematográfica apontou a necessidade de uma retomada na presença estatal nas atividades e no mercado cinematográfico. É nesse momento que há uma intensa e esperançosa atividade que ficará conhecida como retomada do cinema brasileiro e que propiciará a criação, no ano seguinte, da Agência Nacional do Cinema (Ancine).

A Ancine representará o novo projeto nacional para o cinema, que devido aos novos rumos da globalização, não pode mais ter do Estado uma presença tão efetiva economicamente, como aconteceu com a Embrafilme, mas permite desenvolver uma série de ações que possibilitarão, além da regulamentação do mercado, o fomento da construção de uma indústria nacional autossustentável.

A pesquisa realizada tem em foco especialmente o papel da Ancine na elaboração e realização do Plano Nacional de Cultura dos anos 2000, procurando entender suas dificuldades e efetividades no que diz respeito à concretização de uma indústria 


\section{Linguagens - Revista de Letras, Artes e Comunicação - ISSN 1981- 9943 \\ Blumenau, v. 12, n. 2, p. 360-364, mai./ago. 2018. \\ DOI: http://dx.doi.org/10.7867/1981-9943.2018v12n2p361-365}

cinematográfica e do mercado de cinema nacional. Apesar de ser um momento significativo, não houve o milagre da industrialização do cinema brasileiro. Entretanto, nem tudo são frustações, considera Bahia (2012), uma vez que há o alargamento da reflexão sobre o cinema e o audiovisual no Brasil, inserido agora, dentro de uma realidade que não comporta somente a dimensão nacional e que encontra nas novidades tecnológicas, advindas do processo de globalização, novas possibilidades.

No percurso apresentado, não foi possível desconsiderar o impacto da televisão e, especialmente, da Rede Globo na produção audiovisual do país, inclusive por conta da própria aderência do Estado brasileiro à perspectiva de ter no setor televisivo um instrumento para a construção do espírito nacional. Essa relação conflituosa não poderá ser isolada de qualquer reflexão sobre o cinema como indústria no Brasil. E é sobre essa relação que trata o terceiro capítulo Políticas para o desenvolvimento do campo audiovisual nacional: reflexões sobre a relação entre cinema e televisão no Brasil. Nele, o foco são os anos 2000 e discussão sobre a criação de um campo audiovisual.

A Rede Globo, com a criação do seu departamento de cinema, a Globo Filmes, constitui o caso analisado por Bahia (2012). Precisamos considerar que a ação da Globo pretende pôr a empresa como protagonista da relação cinema-televisão e terá efetivas implicações na concepção do campo cinematográfico brasileiro. A produção de minisséries (especialmente, algumas baseadas no universo literário de Ariano Suassuna) são destacadas, por conta de também serem retrabalhadas como filmes, que produzidos pela Rede Globo ganham destaque no cenário nacional, o que comprova o poder de influência da emissora:

\footnotetext{
A entrada da Globo no mercado cinematográfico dá nova vitalidade ao cinema nacional, ao atrair público e renda para essas produções e alargar a cadeia produtiva do filme brasileiro. Quando se consegue apoio de uma major e/ou da televisão, o filme pode vir a se tornar uma grande produção nacional. Ele passa a fazer parte de um circuito mais amplo e atinge maior número de espectadores. O mercado torna-se altamente concentrado e o "padrão Globo de qualidade" passa a estar presente também nas telas de cinema. (BAHIA, 2012, p. 174).
}

Neste longo percurso observado pela sua pesquisa, Lia Bahia (2012) aponta a possibilidade de entender o cinema nacional por outra perspectiva que não somente a artística. Além disso, podemos afirmar que ela lança novas luzes ao debate recente sobre a compreensão do que é fundamental para pensar as necessidades atuais, a fim de tornar a indústria cinematográfica brasileira produtiva, uma vez que foi possível perceber que, “contemporaneamente, a reflexão sobre industrialização precisa atravessar as fronteiras do 


\section{Linguagens - Revista de Letras, Artes e Comunicação - ISSN 1981- 9943 \\ Blumenau, v. 12, n. 2, p. 360-364, mai./ago. 2018.}

DOI: http://dx.doi.org/10.7867/1981-9943.2018v12n2p361-365

cinema e ir em direção ao campo audiovisual integrado, sistêmico e interdependente. Novas questões, desafios e possibilidades se abrem para o debate" (BAHIA, 2012, p. 192).

E seremos nós, agentes culturais, expectadores, pesquisadores, que poderemos abrir caminho para essas novas possibilidades e para restabelecer em graus mais justos a relação entre a produção cinematográfica, o público e o Estado no Brasil. 